\title{
Health promotion: How government can ensure that the National Health Insurance Fund has a fighting chance
}

\author{
M Freeman, ${ }^{1,2}$ MA (Clin Psych); J E Simmonds, ${ }^{2}$ MPH; C D H Parry, ${ }^{2,3}$ PhD (Comm Psych) \\ ${ }^{1}$ Department of Psychology, Faculty of Arts and Social Sciences, Stellenbosch University, Stellenbosch, South Africa \\ ${ }^{2}$ Alcohol, Tobacco and Other Drug Research Unit, South African Medical Research Council, Cape Town, South Africa \\ ${ }^{3}$ Department of Psychiatry, Faculty of Medicine and Health Sciences, Stellenbosch University, Cape Town, South Africa
}

Corresponding author: J E Simmonds (jane.simmonds@mrc.ac.za)

Health promotion - keeping people healthy - is critical to ensuring that South Africa (SA)'s National Health Insurance (NHI) services and funding will not be overwhelmed by having to service and pay for large numbers of people with avoidable disease. Although the $2019 \mathrm{NHI}$ Bill mentions health promotion, its lack of emphasis and the narrow approach proposed in the Bill make it unlikely that health promotion will have significant impact on population health or reducing healthcare need. Health promotion experts submit that there is in fact huge potential for carefully planned and researched health promotion to impact on population health. The establishment of a multisectoral National Health Commission or an independent Health Promotion and Development Foundation linked directly to the NHI Fund that includes several relevant government departments and civil society and researchers is proposed. Of the NHI Fund, $2 \%$ should be dedicated specifically to promoting health and preventing illness, which must support comprehensive, multisectoral health promotion interventions that go beyond awareness raising and health education. SA's specific realities and needs, including poverty and its related behavioural impacts and health consequences, must be taken into account.

S Afr Med J 2020;110(3):188-191. https://doi.org/10.7196/SAMJ.2020.v110i3.14499

National Health Insurance (NHI) in South Africa (SA) will flourish or flounder based on important forthcoming decisions. How to reduce the numbers of people who will require healthcare, and hence minimise the need to draw resources from the proposed NHI Fund, has received inadequate focus. The growing rates of noncommunicable diseases (NCDs), their risk factors and the absence of good, broad-based and multisectoral health promotion interventions may contribute to the collapse of the NHI Fund and its services. For the affordability and sustainability of NHI, the causes of ill health, including the social, economic and commercial determinants, must be addressed. Reducing the numbers of people seeking healthcare can dramatically improve the quality of care provided, including the time spent per patient.

Physical and mental health is desired by most people. A healthy population is also critical for economic and social development. The accumulated losses to SA's gross domestic product between 2006 and 2015 from diabetes, stroke and coronary heart disease are estimated to be $\sim$ ZAR26 billion. ${ }^{[1]}$ The economic cost due to productivity losses arising from absenteeism, lack of presenteeism, and early retirement due to ill health in SA, largely from NCDs, was estimated to be $6.7 \%$ of the GDP in 2015 and is expected to increase to $7.0 \%$ by $2030 .{ }^{[2]}$ As good health is strategically important to the sustainability of the NHI Fund, it would have been expected that health promotion and disease prevention would be high on the agenda of NHI and an important part of the NHI Bill.

The extent to which modifiable risk factors could prevent NCDs in SA has not been calculated. However, the World Health Organization (WHO) estimated that in the Americas $80 \%$ of all heart disease, stroke and type 2 diabetes mellitus (T2DM) and over $40 \%$ of cancer is preventable through multisectoral action. ${ }^{[3]}$ As many countries in the Pan American Health Organization (PAHO) region share socioeconomic similarities with SA, analogous figures are probable in SA. However, without comprehensive approaches to reducing avoidable illness, healthcare costs will escalate hugely. For example, it has been estimated that for diabetes alone in 2018, the public sector costs of diagnosed patients amounted to $\sim$ ZAR2.7 billion, and would be $\sim$ ZAR21.8 billion if both diagnosed and undiagnosed patients are considered. T2DM costs are likely to increase to $\sim$ ZAR35.1 billion in $2030 .^{[4]}$

With current rising rates of many NCD risk factors, increases in the prevalence and costs of various conditions can be expected. For example, hypertension is an important risk factor for cardiovascular diseases and chronic kidney disease and has high comorbidity with diabetes. ${ }^{[5]}$ The global age-standardised prevalence of raised blood pressure in 2015 was $24.1 \%$ in men and $20.1 \%$ in women. ${ }^{[6]}$ In SA in $2016,46 \%$ of women and $44 \%$ of men aged $\geq 15$ years had hypertension. ${ }^{[7]}$ This is almost double the world average. Since 1998, the prevalence of hypertension has nearly doubled, from $25 \%$ to $46 \%$ among women and from $23 \%$ to $44 \%$ among men, although different measuring instruments were used in these surveys. ${ }^{[8]}$ The 2016 South African Demographic and Health Survey indicates high levels of obesity, which has health and cost implications. ${ }^{[8]}$ Only $30 \%$ of women have a body mass index (BMI) in the normal range: $3 \%$ are underweight, 27\% are overweight (BMI $25.0-29.9 \mathrm{~kg} / \mathrm{m}^{2}$ ) and $41 \%$ are obese (BMI $\geq 30),{ }^{[8]}$ with $20 \%$ severely obese (BMI $\geq 35$ ). Of men, $59 \%$ have a BMI in the normal range, $10 \%$ are underweight, $20 \%$ are overweight and $11 \%$ are obese, with $3 \%$ severely obese. ${ }^{[8]}$ Moderate obesity is associated with an $11 \%$ increase in healthcare costs and severe obesity with a $23 \%$ increase. ${ }^{[9]}$ Many other examples would also illustrate the need to promote health for the NHI to thrive.

The NHI Bill presented to Parliament in $2019^{[10]}$ deals almost exclusively with curative and treatment approaches. However, two 
sections mention health promotion: section 37(1) refers to health promotion being managed as part of a contracting unit to manage the provision of primary healthcare services, and section 57.4(f) considers the need for the purchasing of healthcare service benefits, including health promotion. ${ }^{[10]}$ However, they are limited in their scope and the potential of health promotion to significantly impact on health. Contracting units, comprising a district hospital, clinics or community health centres and ward-based outreach teams and private providers, which have numerous requirements to provide curative services and limited resources to meet a growing demand for treating illness, are unlikely to give adequate attention to health promotion, or provide sufficient funding from their allocations for it. No provision is made for health promotion activities at national or provincial levels, despite this being where many interventions are required, including regulatory actions.

In 2017, the government document 'NHI implementation: Institutions, bodies and commissions that must be established' was circulated for public comment. ${ }^{[1]}$ It stated that 'promoting health and preventing illness is central to NHI and to social and economic growth and development in South Africa' and that a structure should be set up to deal with determinants of health, including social determinants, which would be part of NHI. ${ }^{[11]}$ A National Health Commission was proposed, with the primary objective and purpose of addressing 'the social determinants of health through a multi-sectoral and development approach involving key government departments and non-state actors'. ${ }^{[11]}$ This commission would 'co-ordinate key sectors in implementing "a health in all policies" and an all-inclusive approach to the prevention and control of NonCommunicable Diseases, including mental health. ${ }^{[11]}$ Recognition of the need for the establishment of this structure was the realisation of a resolution taken by the African National Congress in 2007 that such a commission should be established by 2013. ${ }^{[12]}$ However, in later iterations of $\mathrm{NHI}$ and the Bill published for comment, this important proposal for setting up a structure aimed at addressing health promotion and subsequently reducing numbers of individuals needing healthcare has disappeared.

\section{Health promotion and its potential to assist a successfull NHI}

Among many different reasons why health promotion is not prominent in the NHI Bill and in current NHI discussions is that the Fund is likely to struggle to meet the demand for quality curative care. All funds must therefore be made available to pay for such services. Another possible reason is that there is a high degree of scepticism, even in the health sector and among health leadership, regarding the efficacy of health promotion to reduce healthcare needs and costs. Many leaders are aware that several critical causes of ill health, such as poverty, lie outside direct health interventions, and therefore have low expectations of what health promotion can achieve. However, a broad approach to health promotion includes addressing both proximal and distal causes of health problems and involves multisectoral intervention. The WHO's global business case for NCDs shows that if low- and low-to-middle-income countries put in place the most cost-effective interventions for NCDs, most of which are promotive/preventive, by 2030 they will see a return of USD7 per person for every dollar invested. ${ }^{[13]}$

To better understand SA's current health promotion situation, and to ascertain where health promotion should go to in the future, the South African Medical Research Council contracted the first author (MF) to interview $12 \mathrm{key}$ local health promotion experts (selected through a snowball method) working in government, research and non-governmental sectors. The primary focus was on health promotion and NCDs. The interviewees all agreed that health promotion is underperforming in its potential to contribute to population health outcomes and has not been given adequate opportunities to prove its efficacy and effectiveness. Comments included that health promotion is 'fragmented and vertical', 'underfunded', 'culturally out of touch', 'not enabling' and 'not attended to'. However, its potential to be a game changer and a cost-effective means of improving health in the country was expressed by all interviewees, although the potential of health promotion to improve health would require far more attention and resources than health promotion currently receives, and greater attention to local conditions and causes of ill health. Most respondents felt strongly that funding for health promotion was 'laughable, and consequently the discipline was largely unable to show what it could achieve. A problem identified in the interviews was that in health promotion, especially for NCDs, the results of improved health are not immediate, and there is an impatience (especially in government) to see investment outcomes within a short space of time. Experts also bemoaned the fact that money for health promotion gets spent on superficial and untested health information and education campaigns with little impact, reflecting the narrow view of health promotion that many hold. Opportunities to comprehensively and definitively show what health promotion can achieve, especially on a large scale, are limited. This lack creates a circularity in which insufficient evidence is available to show efficacy, resulting in insufficient resources for health promotion and evidence being generated to inform interventions.

There is also concern that much evidence for health promotion is not produced in SA, or in countries with similar socioeconomic and demographic characteristics. The WHO has published several costeffective NCD policy options, dubbed 'best buys', that are included in the Global Action Plan for the prevention and control of NCDs. These represent the de facto global strategy to control NCDs. ${ }^{[14]}$ Although the reasoning behind the 'best buys' is not controversial, ${ }^{[15]}$ it is likely that context-specific factors may influence their effectiveness. To assess what evidence for these recommendations comes from low- and low-to-middle-income countries, a systematic analysis was conducted. ${ }^{[15]}$ The main findings of this review were that there is a general lack of published evidence for the 'best buy' interventions in low- and middle-income countries, and many interventions have not been evaluated in these settings. ${ }^{[15]}$ Only five studies were found from the African region, ${ }^{[15]}$ reinforcing the view that there is insufficient knowledge to put resources into health promotion.

Experts interviewed agreed that more local research is needed regarding different health promotion alternatives, taking into account SA's unique context and cultural complexity, and that comprehensive evaluations on NCD health promotion are needed to determine the efficacy and effectiveness of certain interventions. However, this should not deter the country from immediately embarking on concerted health promotion programmes. Interviewees agreed that there is sufficient global and local knowledge about the causes of ill health and a range of wellconceived, theoretically sound, and some well-tested (albeit not all local) health promotion strategies, many structural or regulatory in nature. It is irresponsible to suggest no action until these are all researched locally; this would lead to avoidable morbidity and mortality and the need for more health services. However, once employed, these interventions should be thoroughly evaluated, which will decide whether or not they are continued and expanded. Additional evidence for innovative health promotion interventions that are based on local conditions and cultural differences should also be generated. Many interviewees stated that SA's NHI Fund offers an excellent opportunity to do this. 
Experts were unanimous that health promotion requires a multisectoral approach and that a structure is needed to facilitate this, preferably a Health Promotion and Development Foundation, ${ }^{[16]}$ or the National Health Commission referred to earlier. Health promotion must deal with the direct causes of ill health and with the upstream determinants of the causes. Health promoters and community health workers must be supported by epidemiologists and health promotion experts who are able to examine the social, economic and commercial determinants of health, including where and how people live, work and survive, and how to redress the obstacles to better health. The National Department of Health $(\mathrm{NDoH})$ and indeed the health sector as a whole must then act in partnership with other sectors and departments to promote health in communities.

Several interviewees referred to the Thai Health Promotion Foundation (Thai-Health) as an example of a health promotion structure to be emulated. When Thailand started their NHI, they simultaneously established Thai-Health to focus on promotion and prevention issues, which has contributed significantly to the success of NHI. ${ }^{[17]}$ Thai-Health develops its policies and plans based on a triad of scientific evidence, social movement and political involvement. ${ }^{[16]}$ It also carefully monitors their impact. Its focus is on the major NCD risk factors, i.e. tobacco, alcohol, physical activity and diet. However, where poverty, for example, is considered to be impeding people's ability to eat healthy foods, the structure allows them to involve ministries that can assist, such as Treasury, Agriculture and Trade and Industry. Thai-Health also funds evidence generation, campaigns and social mobilisation to address NCD risk factors. ${ }^{[17]}$ For a population of $\sim 69$ million, the amount allocated to the Foundation is around USD120 million (ZAR1.8 billion). This translates to a per capita expenditure of $\sim$ USD1.7 (ZAR25) per annum..$^{[17]}$ Using the resources allocated, Thai-Health managed to reduce tobacco smoking from $22.5 \%$ of the population in 2001 to $18.2 \%$ in 2014 and the annual per capita alcohol consumption from 8.1 litres in 2005 to 6.9 litres in 2014 , and to increase the percentage of the adult population doing at least 150 minutes of moderate-intensity exercise or 75 minutes of intensive exercise per week from $66.3 \%$ in 2012 to $72.9 \%$ in $2017 .{ }^{[17]}$

Interviewees noted that many health promotion interventions are not costly, and certain health promotion interventions can reduce health risks and bring additional resources to the state. SA has been at the forefront of introducing legislation and regulations that cost little but appear to be having significant impact. For example, it is anticipated that the recent levy on sugar-sweetened beverages will avert an estimated 8000 premature deaths related to T2DM over 20 years. Government would save ZAR2 billion in subsidised healthcare and raise ZAR6 billion in tax revenues per annum. ${ }^{[18]}$ Other health-promoting actions include tobacco legislation and taxation; increased taxation of alcohol, better labelling of alcohol containers and legislating against the sale of beer in ever-larger containers; and regulations on trans fats and salt. Notwithstanding these highly effective low-cost interventions, there are many health promotion activities, including community- and city-based projects, that need reasonable funding to be successful. These must be adequately funded to achieve a positive cost dividend relative to curative care.

\section{What proportion of the NHI Fund should be allocated to health promotion and illiness prevention?}

The proportion of health spending that currently goes towards prevention/promotion in SA is unknown, and is highly variable globally. Even in more developed countries, the percentage spent on prevention/promotion varies significantly. In the Organisation for Economic Co-operation and Development (OECD) countries, it ranges from just over $1 \%$ in the Slovak Republic to over $6 \%$ in Canada, with a mode of $3 \% \cdot{ }^{[19]}$ It is also uncertain whether even at the higher levels this is adequate to impact effectively on health outcomes. Nonetheless, it is recommended that at least $2 \%$ of health expenditure in SA should be put towards health promotion. If $2 \%$ of SA's current health expenditure of ZAR400 billion is allocated, ZAR8 billion would be available specifically for health promotion activities and interventions. Different government departments, civil society and researchers, and not just the $\mathrm{NDoH}$, could then access this funding for a wide range of health promotional projects and programmes. For example, subsidising healthy foods for the poorer/ poor communities as part of poverty alleviation, or assisting with open-access exercise parks in townships, could be done using part of this fund.

\section{Conclusions}

SA aims to achieve Sustainable Development Goal 4.3 of reducing premature mortality from NCDs by one-third by $2030 .{ }^{[20]}$ However, it is unlikely that this will be achieved without multisectoral and well-funded health promotion interventions that are focused on local realities and address health determinants. Many factors will determine whether NHI improves health status and brings goodquality healthcare for all in SA. One of the most important will be the extent of demand for health services. This demand can be reduced, but requires the NHI Act to incorporate broadly defined health promotion as an integral element and commit to health promotion and disease prevention through a financial allocation from the NHI Fund, and the establishment of an intersectoral structure to promote health and champion a broad range of activities in this area.

\section{Declaration. None.}

Acknowledgements and funding. The authors acknowledge funding from the South African Medical Research Council for covering their salaries and thereby facilitating their preparation of this manuscript.

Author contributions. All authors were involved in planning the work that led to the preparation of this manuscript. MF wrote the first draft, and the other authors contributed substantially to subsequent revisions. Conflicts of interest. None.

1. Abegunde DO, Mathers CD, Adam T, Ortegon M, Strong $\mathrm{K}$. The burden and costs of chronic diseases in low-income and middle-income countries. Lancet 2007;370(9603):1929-1938. https://doi. diseases in low-income and middle-incor
org/10.1016/S0140-6736(07)61696-1

2. Rasmussen B, Sweeney K, Sheehan P. Economic costs of absenteeism, presenteeism and early 2. Rasmussen B, Sweeney K, Sheehan P. Economic costs of absenteeism, presenteeism and early
retirement due to ill health: A focus on South Africa. Report to the US Chamber of Commerce. Melbourne: Victoria Institute of Strategic Economic Studies, 2008. https://www.uschamber.com/sites default/files/south_africa_summary_feb_final_draft_with_catherine_mellor_note.pdf (accessed 4 February 2020).

3. Pan American Health Organization, Non-communicable diseases in the Americas: All sectors of society can help solve the problem. Issue brief on non-communicable diseases. https://www.paho.org hq/dmdocuments/2011/paho-policy-brief-1-En-webl.pdf (accessed 8 October 2019).

4. Erzse A, Stacey N, Chola L, Tugenhaft A, Freeman M, Hoffman K. The direct medical cost of type 2 diabetes mellitus in South Africa: A cost of illness study. Glob Health Action 2019;12(1):1636611. https://doi.org/10.1080/16549716.2019.1636611

5. Norman R, Gaziano T, Laubscher R, et al. Estimating the burden of disease attributable to blood pressure in South Africa in 2000. S Afr Med J 2007;97(8):692-698. https://doi.org/10.1080/22201009. pressure in Sout.10872159

6. Zhou B, Bentham J, di Cesare M, et al. Worldwide trends in blood pressure from 1975 to 2015 Zhou B, Bentham J, di Cesare M, et al. Worldwide trends in blood pressure from 1975 to 2015 ;
A pooled analysis of 1479 population-based measurement studies with 19.1 million participants. A pooled analysis of 1479 population-based measurement studies with 19.1
Lancet 2017;389(10064):37-55. https://doi.org/10.1016/S0140-6736(16)31919-5

Lancet 2017;389(10064):37-55. https://doi.org/10.1016/S0140-6736(16)31919-5
7. Statistics South Africa. Demographic and Health Survey 2016. Key indicator report. Pretoria: Stats Statistics South Africa. Demographic and Health Survey 2016. Key indicator report. Pretoria: Stats
SA, 2017. https://www.statssa.gov.za/publications/Report\%2003-00-09/Report\%2003-00-092016.pdf (accessed 4 February 2020).

8. National Department of Health, South Africa, Statistics South Africa, South African Medical Research Council, and ICF. South Africa Demographic and Health Survey 2016. Pretoria, South Africa, and Rockville, Md, USA: NDoH, Stats SA, SAMRC and ICF, 2019. https://www.dhsprogram.com/ publications/publication-fr337-dhs-final-reports.cfm (accessed 4 February 2020).

9. Sturm R, An R, Maroba J, Patel D. The effects of obesity, smoking, and excessive alcohol intake on healthcare expenditure in a comprehensive medical scheme. S Afr Med J 2013;103(11):840-844 https://doi.org/10.7196/SAMJ.7260 
10. Republic of South Africa. National Health Insurance Bill. Government Gazette No. 42598 of 26 July 2019. https://www.gov.za/sites/default/files/gcis_document/201908/national-health-insurance-bill-b-11 2019.pdf (accessed 4 February 2020)

11. National Department of Health, South Africa. NHI implementation: Institutions, bodies and commissions that must be established. Pretoria: $\mathrm{NDoH}, 2017$.

12. African National Congress. Education, health, science \& technology: ANC discussion document African National Congress. Education, health, science \& technology: ANC discussion document
2017. https://www.politicsweb.co.za/news-and-analysis/education-health-science--technology-anc2017. https://www.politicsweb.co.2
discussio (accessed 8 October 2019)

13. Bertram M, Sweeny K, Lauer J, et al. Investing in non-communicable diseases: An estimation of the return on investment for prevention and treatment services. Lancet 2018;391(10134):2071-2078. https://doi.org/10.1016/S0140-6736(18)30665-2

4. World Health Organization. Global Action Plan for the Prevention and Control of Noncommunicable Diseases 2013 - 2020. Geneva: WHO, 2013. https://apps.who.int/iris/bitstream/ handle/10665/94384/9789241506236_eng.pdf;jsessionid=83DE72FE480F7FFA840BFD74EAE7A8DE ?sequence $=1$ (accessed 14 October 2019).

15. Allen LN, Pullar J, Wickramasinghe KK, et al. Evaluation of research on interventions aligned to WHO 'Best Buys' for NCDs in low-income and lower middle-income countries: A systematic review from 1990 to 2015. BMJ Glob Health 2018;3(1). https://doi.org/10.1136/bmjgh-2017-000535
16. Perez G, Ayo-Yusuf O, Hofman K, et al. Establishing a Health Promotion and Development Foundation in South Africa. S Afr Med J 2013;103(3):147-149. https://doi.org/10.7196/SAMJ.6281

7. Pongutta S, Suphanchaimat R, Patcharanarumol W, Tangcharoensathien V. Lessons from the Thai Pongutta S, Suphanchaimat R, Patcharanarumol W, Tangcharoensathien V. Lessons from the Thai
Health Promotion Foundation. Bull World Health Organ 2019;97:213-220. https://doi.org/10.2471/ BLT.18.220277

18. Saxena A, Stacey N, Puech PDR, et al. The distributional impact of taxing sugar-sweetened beverage: Findings from an extended cost-effectiveness analysis in South Africa. BMJ Glob Health 2019;4:e001317. https://doi.org/10.1136/bmjgh-2018-001317

19. Gmeinder M, Morgan D, Mueller M. How much do OECD countries spend on prevention? OECD Health Working Papers, No. 101. 15 December 2017. https://doi.org/10.1787/f19e803c-en

20. United Nations. Sustainable Development Goals. 2016. https://www.un.org/sustainabledevelopment/ sustainable-development-goals/ (accessed 8 October 2019).

Accepted 26 November 2019 